\title{
Importância e medidas de controle para Alphitobius diaperinus em aviários
}

\author{
Importance and measures of control for Alphitobius diaperinus in poultry houses
}

Anne Karoline Japp ${ }^{\mathrm{I}}$ Carla de Lima Bicho"I Ana Vitória Fischer da Silva ${ }^{\text {III }}$

\section{- REVISÃO BIBLIOGRÁFICA -}

\section{RESUMO}

O crescimento da produção avícola provocado pela alta demanda do mercado acarreta um aumento da criação de aves em confinamento, o que resulta em um aumento da densidade das aves dentro do galpão. Em função disso, há um incremento da umidade da cama aviária, proveniente tanto das excretas das aves, como da água dos bebedouros, que favorece o crescimento de populações do coleóptero Alphitobius diaperinus, popularmente conhecido como cascudinho. O contato direto do inseto com a cama das aves, assim como a alimentação a partir de aves moribundas e mortas, faz do A. diaperinus um veiculador de diversos patógenos, sendo destacados bactérias, protozoários e vírus que causam imunossupressão nas aves. Além da relação com os patógenos, os cascudinhos podem provocar danos nas instalações avícolas, pois, na fase larval, escavam túneis no material isolante para empuparem e destroem a proteção de poliuretano usada para isolamento térmico dos galpões em países de clima frio, a qual precisa ser trocada a cada dois ou três anos. Outro fator prejudicial às aves é a substituição da ração balanceada por larvas e adultos do coleóptero, uma vez que afeta o ganho de peso, principalmente, das mais jovens. Frente ao exposto, a presença do cascudinho em instalações avícolas torna-se um problema, tanto sanitário, como financeiro. $\mathrm{O}$ controle do $\mathbf{A}$. diaperinus é considerado difícil, e inseticidas químicos são comumente utilizados em aviários, mas apresentam desvantagens, pois deixam resíduos na carcaça, bem como no meio ambiente. A presença de alta quantidade de matéria orgânica nos aviários provoca a diminuição da efetividade dos inseticidas químicos. Vários estudos vêm sendo desenvolvidos na busca de alternativas, como, por exemplo, nematoides e fungos entomapatogênicos, mas até o momento não são produzidos em escala comercial. Outra linha de pesquisa é a utilização de terra diatomácea, um pó-inerte que não deixa resíduos na carne de frango e no ambiente.

Palavras-chave: cascudinho, fungos entomopatogênicos, nematoides, terra diatomácea.

\begin{abstract}
The growth in poultry production because of the high market's demand causes an increase in the confinement raising, which increases the density of birds in poultry houses. As a result of this function, there is moisture increase in broiler litter, both from the excreta and drinkers, which favors the growth of the coleopterons Alphitobius diaperinus, popularly known as darkling beetle. The direct contact of the insects with the broiler litter as well as their feeding from dead and sick broilers make the A. diaperinus a vehicle for various pathogens, especially bacteria, protozoa and viruses. Besides the relationship with the pathogens, the darkling beetle can cause damage to poultry house, because at the larva stage they tent to burrow in to the insulating material and destroying the protection of polyurethane used for thermal insulation of poultry houses in countries with cold climate, which have to be changed every two or three years. Another harming factor to the broilers is the replacement of theirs balanced diet for larvae and adults of coleopterons, which affect the weight gain, mainly within younger individuals. Due to this factor, the presence of darkling beetle in poultry installations becomes a health as well as financial problem. The control of A. diaperinus is regarded as difficult and the use of chemical insecticides is common in poultry raising, even though it has disadvantages because it leaves residue in the carcass and in the environment. The presence of high amount of organic matter in poultry causes the decrease of the effectiveness of chemical insecticides. Several studies have been developed in research for alternatives, such as nematodes, fungi entomopathogenics, but they are not yet available commercially. Another line of research is the use of diatomaceous earth, an inert and non toxic powder which leaves no residues in chicken meat or in the environment.
\end{abstract}

Key words: diatomaceous earth, entomopathogenic fungi, lesser mealworm, nematode.

'Pós-graduação em Ciências Veterinárias, Universidade Federal do Paraná (UFPR), 80620-360, Curitiba, PR, Brasil. E-mail: annejapp@hotmail.com. Autor para correspondência.

"Departamento de Biologia, Universidade Estadual do Paraíba (UEPB), Campina Grande, PB, Brasil.

II'Departamento de Fisiologia Animal, UFPR, Curitiba, PR, Brasil. 


\section{INTRODUÇÃO}

O cascudinho, originário do continente Africano (VAUGHAN et al., 1984), é uma praga secundária de grãos armazenados com problemas de umidade durante o seu acondicionamento e que provavelmente migrou para os aviários através do alimento ou de fazendas vizinhas que estocavam alimentos (WALLACE et al., 1985).

A demanda do mercado, cada vez mais crescente, força a criação desses animais em confinamento, o que acarreta um aumento da densidade das aves dentro do galpão. Como consequência, observa-se o incremento da umidade na cama aviária, proveniente tanto das excretas das aves, como da água dos bebedouros, o que favorece o crescimento dos cascudinhos.

\section{Alphitobius diaperinus}

O cascudinho, quando associado a tal agroecossistema, alimenta-se de aves moribundas, das carcaças, das fezes e da ração de aves (LESCHEN \& STEELMAN, 1988). O ciclo biológico de Alphitobius diaperinus se completa em 55 dias, em temperatura de $27^{\circ} \mathrm{C}$ e $80 \%$ de UR. Após cinco dias da postura, eclode de cada ovo uma larva esbranquiçada, com 1,5mm de comprimento. A fase larval estende-se por 38 dias, quando os imaturos atingem o tamanho de $13,8 \mathrm{~mm}$ de comprimento e coloração marrom escura. As larvas passam por até 11 estágios de desenvolvimento (VERGARA \& GAZANI, 1996). Após a fase larval, sofrem ecdise e empupam por cinco dias, emergindo adultos de coloração branca, que, após quatro dias, adquirem coloração característica (marrom). Os adultos começam a se reproduzir 20 dias após a emergência (SCHAFER DASILVAet al., 2005).

A estrutura espacial dessa população de insetos no solo, em uma granja avícola, apresenta alta heterogeneidade; as larvas de últimos estágios de vida, pupas e adultos, são localizadas no solo, cerca de $10 \mathrm{~cm}$ de profundidade, preferencialmente abaixo dos comedouros, onde o substrato apresenta-se denso, compactado e com umidade baixa. Esses insetos, em reduzidas temperaturas e/ou situações de estresse, não realizam diapausa, como os demais insetos, migrando em movimentos verticais para baixo em direção ao solo (SALIN et al., 2000).

O ciclo biológico do cascudinho está diretamente relacionado à temperatura. Foi observado que a $22^{\circ} \mathrm{C}$ o tempo de desenvolvimento de suas fases é maior, porém a sobrevivência é baixa, e que a temperatura de $31^{\circ} \mathrm{C}$ foi considerada a mais adequada para o desenvolvimento das fases imaturas, com alta sobrevivência. Temperaturas baixas (inferiores a $16,5^{\circ} \mathrm{C}$ ) podem contribuir de maneira eficiente para o controle desses insetos, uma vez que não ocorre o desenvolvimento das fases imaturas, o que leva a uma diminuição da população (CHERNAKI \& ALMEIDA, 2001).

O contato direto do inseto com a cama das aves, assim como se alimentar de aves moribundas e mortas, faz do A. diaperinus um veiculador de diversos patógenos aviários (AXTELL \& ARENDS, 1990).

CHERNAKI-LEFFER et al. (2002), ao isolarem enterobactérias de adultos de $\boldsymbol{A}$. diaperinus e da cama de aviários em diferentes granjas do Oeste do Estado do Paraná, assinalaram as seguintes espécies: Proteus vulgaris, P. mirabilis, Escherichia coli, Enterobacter agglomerans, E. gergoviae, E. sakazakii, Citrobacter diversus e Klebsiella pneumoniae, enquanto que, na cama, foram encontradas $\boldsymbol{P}$. vulgaris, $\boldsymbol{P}$. mirabilis, Escherichia coli e Enterobacter agglomerans. Não foram isoladas Salmonella spp. dos insetos nem da cama. A enterobactéria $\boldsymbol{P}$. vulgaris foi predominante nas camas das granjas (71,4\%), e E. coli foi a segunda mais frequente, isolada nos insetos em $42,8 \%$ das granjas. SEGABINAZI et al. (2005) coletaram cascudinhos em empresas avícolas dos Estados do Rio Grande do Sul e de Santa Catarina e os analisaram por meio de métodos de bacteriologia convencional. Foram isoladas 14 espécies pertencentes a 10 gêneros diferentes de bactérias Enterobacteriaceae nas superfícies externa e interna dos insetos: Citrobacter freundii (6,89\%), Edwardsiella ictalurio (6,89\%), Enterobacter aerogenes (5,07\%), E. (Pantoea) agglomerans (0,37\%), E. gergoviae (2,53\%), Escherichia coli (36,96\%), Klebsiella oxytoca (4,34\%), K. pneumoniae (18,11\%), Proteus mirabilis (8,34\%), P. vulgaris (1,44\%), Serratia marcescens (1,44\%), Yersinia enterocolitica (0,37\%), Salmonella sp (0,37\%) e Cedecea sp. (6,89\%). A maior frequência de isolados bacterianos e da diversidade de espécies foi observada na superfície externa (exoesqueleto) do inseto.

VITTORI et al. (2007) isolaram a bactéria Clostridium perfringens, causador de enterite necrótica, por meio de métodos bacteriológicos convencionais de amostras de A. diaperinus provenientes de Sertãozinho, São Paulo (SP), e Descalvado (SP).

Segundo trabalho realizado por GOODWIN \& WALTMAN (1996), em insetos coletados de sete aviários diferentes do Estado da Geórgia, nos Estados Unidos, foi verificada a existência do protozoário Eimeiria sp., causador de coccidiose intestinal em aves, de reovírus e de herpesvírus. A. diaperinus 
demonstra também ser um potencial transportador de outras viroses aviárias, como a Doença de Newcastle e Gumboro (MCALLISTER et al., 1995), bem como de fungos, como Aspergillus flavus, A. glaucus e Candida spp. (CASAS et al., 1968), e como hospedeiro intermediário do cestódeo Choanotaenia infundibulum (ELOWI, 1977).

Alphitobius diaperinus não só causa doenças aos animais, mas também aos humanos. Estudos atestam que pesquisadores, após dois anos de estudos e manipulação dessa espécie, começaram a apresentar sintomas alérgicos, urticárias, angioedema, asma e conjuntivite (SCHROCKENSTEIN et al., 1988).

Além da relação com os patógenos, os cascudinhos podem provocar danos nas instalações avícolas ao destruírem a proteção de poliuretano usada para isolamento térmico dos galpões em países de clima frio, o que implica a troca da estrutura a cada dois ou três anos. Os danos supracitados são ocasionados pela ação das larvas que escavam túneis no material isolante para empuparem (VAUGHAN et al., 1984; DESPINS et al., 1987). No Brasil, há registro de danos similares na estrutura de madeira que compõe as gaiolas (FERNANDES et al., 1995).

Outro fator prejudicial às aves é a substituição da ração balanceada por larvas e adultos do coleóptero, em razão do comportamento que possuem de comer qualquer objeto em movimento, o que afeta principalmente as mais jovens. DESPINS \& AXTELL (1995) avaliaram o comportamento alimentar e o crescimento de frangos de corte alimentados com larvas de cascudinhos. A diferença do peso médio corporal de aves alimentadas com larvas foi de 173g, significativamente menor daquelas que só receberam ração. Além de o peso médio corporal ser menor, as aves mostraram sinais de estresse durante o período de alimentação com larvas e apresentaram alta vocalização, fezes aguadas e com presença de cutícula larval.

Muitas aves, ao ingerirem os adultos, podem sofrer danos causados pelos élitros, lesionando o trato gastrointestinal e, portanto, deixando-o vulnerável à entrada de patógenos (MATIAS, 1995; JAPP et al., 2008).

\section{Controle}

O controle do A. diaperinus é considerado difícil, já que seus inimigos naturais são pouco conhecidos e até os dias de hoje não existe nenhum método eficiente e seguro. Os químicos usados no controle são de difícil aplicação em razão dos ambientes habitados por esses insetos, tais como o solo, os locais com grande quantidade de matéria orgânica (excreta, ração e cepilho), entre as cortinas e as frestas dos galpões, o que inviabiliza a ação dos produtos. Normalmente, resultados pouco expressivos estão relacionados à inadequada aplicação do produto (ARENDS, 1987).

Há algum tempo, o controle dessa praga é realizado por meio do uso de produtos químicos, como, por exemplo, os piretroides e organofosforados. Porém, estes apresentam algumas desvantagens, como seleção de populações de insetos resistentes e contaminação do ambiente e das aves, tornando-se uma barreira comercial para exportação de carne, pois a União Europeia não permite o uso de determinados produtos químicos para o controle de insetos, já que estes podem provocar resíduo na carcaça.

CHERNAKI-LEFFER et al. (2006) avaliaram a suscetibilidade de reguladores de crescimento clorfluazuro, triflumurum, diflubenzurom, lufenurom e metoxifenozide em larvas de cascudinhos em condições de laboratório. As larvas, separadas em médias $(0,7 \mathrm{~cm}$ de comprimento) e grandes $(1,3 \mathrm{~cm})$, foram alimentadas com ração para coelhos e tratadas com concentrações de 16 e 200ppm de ingrediente ativo. Metoxifenozide causou mortalidade máxima de 33,3\% em larvas grandes a 160ppm, demonstrando ser pouco tóxico para larvas de A. diaperinus. Diflubenzurom causou mortalidade entre 39,9 e $53,3 \%$ na mesma dose, e a $10 \mathrm{ppm}$ a mortalidade não ultrapassou 13,3\%. Lufenurom causou mortalidade máxima de $56,7 \%$ a $10 p p m$ e de $63,3 \%$ a 160ppm. Triflumurom apresentou significativa diferença na porcentagem de mortalidade entre as doses de $10 \mathrm{e}$ 160ppm (10 e 76,7\%, respectivamente). Clorfluazurom causou mortalidade de 76,7\% a 10ppm. As larvas do grupo testemunha apresentaram mortalidade de até $17,8 \%$.

Trabalhos visando ao controle de $\boldsymbol{A}$. diaperinus vêm sendo desenvolvidos com o uso de nematoides e fungos entomopatogênicos. ALVES et al. (2005) avaliaram a patogenicidade de nematoides entomopatogênicos Steinernema glaseri e $\boldsymbol{S}$. carpocapsae em larvas e adultos de cascudinhos. Os autores imergiram os insetos em solução contendo os nematoides nas concentrações de 60 e 120JI inseto-1 (JI - Juvenis Infectivos). Entre os isolados avaliados, S. carpocapsae, nas concentrações de 60 e $120 \mathrm{JI}^{\text {inseto }}{ }^{-1}$, resultou em 17 e $48 \%$ de mortalidade larval, respectivamente; esse nematoide não foi testado em adultos. Quando foi utilizado o $S$. carpocapsae, a mortalidade de larvas e adultos, na concentração de $60 \mathrm{JI}$ inseto $^{-1}$, foi de 40 e $26,7 \%$, respectivamente. O nematoide $\boldsymbol{S}$. glaseri, nas concentrações de 60JI inseto ${ }^{-1}$, causou 1,7 e $0 \%$ de mortalidade de larvas e adultos, respectivamente, enquanto que, na concentração de 
120JI inseto ${ }^{-1}$, a mortalidade de larva e adulto foi de $3,3 \%$ para ambos. Verificou-se que as larvas foram mais susceptíveis que os adultos e que os dois isolados de S. carpocapsae foram mais patogênicos.

Os nematoides entomopatogênicos agem em associação com bactérias, em uma relação simbiótica mutualística, e por meio de diferentes estratégias de busca localizam hospedeiros potenciais, invadindo-os através de aberturas naturais. Uma vez na hemocele do inseto, liberam as bactérias associadas, as quais matam o hospedeiro em 24 e 72 horas após a invasão. Bactérias e nematoides se multiplicam no interior do corpo do inseto e, após duas a três gerações, tem início a formação de juvenis infectantes (JI), os quais abandonam o cadáver à procura de novos hospedeiros (AGUILLERA et al., 2001).

SILVA et al. (2006) avaliaram a ação do fungo

Beauveria bassiana, nas concentrações de $3,4 \times 10^{6}$ e $3,4 \times 10^{8}$ conídios $\mathrm{ml}^{-1}$, sobre o ciclo biológico do cascudinho $\boldsymbol{A}$. diaperinus em laboratório. $\mathrm{Na}$ concentração de $3,4 \times 10^{6}$, $54 \%$ dos ovos tratados estavam inférteis, houve $54 \%$ de mortalidade de larvas tratadas nos estádios I, II e II, 22,5\% nos estádios IV, V e VI, 9,5\% nos estádios VII e VIII e 24,5\% de mortalidade das pupas. Na concentração de $3,4 \times 10^{8}$ conídios $\mathrm{ml}^{-1}$, $66,8 \%$ dos ovos tratados estavam inviáveis, ocorrendo mortalidade de $56 \%$ das larvas tratadas nos estádios I, II e II, 34\% nos estádios IV, V e VI, 24,5\% nos estádios VII e VIII e 49,5\% das pupas. Já no controle, 13,3\% dos ovos estavam inviáveis, ocorrendo mortalidade de $10 \%$ nos estádios I, II e III, 4\% nos estádios IV, V, VI e 0\% de mortalidade nos estágios VII, VIII e em pupas. Sobre o cascudinho adulto, o fungo não teve efeito nocivo em nenhum grupo analisado.

Até o momento, produtos à base de nematoides e fungos entomopatogênicos não estão sendo produzidos em escala comercial, apenas laboratorial para avaliar a efetividade, necessitando de maiores estudos em relação ao seu modo de aplicação nos aviários.

Um dos produtos que vem sendo estudado como controle alternativo e seguro, não químico, é a terra diatomácea (TD), um pó inerte composto por carapaças de algas diatomáceas fossilizadas (KORUNIC, 1998), formadas, principalmente, por sílica. Os pós inertes aderem à epicutícula dos insetos por carga eletrostática e atuam por abrasão e adsorção de lipídios epiticulares (EBELING et al., 1966). Consequentemente, os insetos morrem por desidratação quando cerca de $60 \%$ de água ou $30 \%$ da massa corporal total é perdida (EBELING, 1971). Segundo KORUNIC (1998), o uso de TD no tratamento de grãos armazenados contra insetos apresenta vantagens sobre os inseticidas químicos, pois são de fácil remoção, atóxicos e não deixam resíduos nos grãos tratados. A ação inseticida da TD depende de vários fatores-chave, tais como a presença de um tamanho uniforme entre as partículas ( $10 \mu \mathrm{m}$ ou menos), uma ótima atividade de superfície, a alta adsorção de gordura e a alta quantidade de óxido de sílica amorfa e de um $\mathrm{pH}$ abaixo de 8,5.

Não existe evidência de efeito tóxico agudo ou crônico da terra diatomácea, não se mostrando perigoso quando consumido por mamíferos. Estudos com ratos mostram que, quando alimentados com dietas contendo $5 \%$ de terra diatomácea, nenhum sinal de anormalidade é observado após 90 dias (BERTKE, 1964). De acordo com a Agência Internacional de Pesquisas do Câncer, a terra diatomácea pertence ao grupo 3, classificada como não cancerígena. Ratos submetidos à inalação de ar contendo 5 a 80mg de terra diatomácea em $1 \mathrm{~m}^{3}$ apresentaram imperceptíveis reações em seus pulmões (OMURA, 1981).

O uso da terra diatomácea é permitido desde 1961 em produtos estocados e alimentos processados industrialmente nos Estados Unidos da América e como protetor de grãos armazenados no Canadá, na Austrália, no Japão, na Indonésia, Arábia Saudita e na Croácia (ANON, 1961).

Estudos mostram uma relação da terra diatomácea no controle de muitos animais, tais como: cupins, lagartas, besouros desfolhadores, pulgas, grilos, lesmas e diplópodos (KORUNIC, 1998). Pode ser usada como parte da estratégia de manejo integrado de pragas em grãos armazenados e na indústria de alimentos processados, como também na proteção de grãos e como inseticida residual (KORUNIC et al., 1996).

Estudos demonstram que a terra diatomácea apresenta resultados satisfatórios no controle dos coleópteros-praga de grãos armazenados, como, por exemplo, Prostephanus truncatus (Bostrichidae), Sitophilus zeamais (Curculionidae), Callosobruchus maculatus e Acanthoscelides obtectus (Bruchidae) (STATHERS et al., 2004).

PINTO JUNIOR et al. (2005) avaliaram seis diferentes dosagens de TD no controle de Acanthoscelides obtectus (Bruchidae). Os adultos

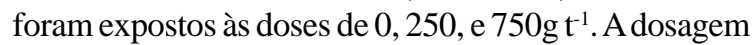
de $750 \mathrm{~g} \mathrm{t}^{-1}$ atingiu maior nível de controle, sendo 78,5\%, para o um período de exposição de cinco dias, e de $100 \%$, aos 10 dias. A dosagem de $250 \mathrm{~g} \mathrm{t}^{-1}$ apresentou menor eficácia, com 54,2\% da população aos cinco dias, e de 98,3\%, aos 10 dias. Aos 141 dias, todas as dosagens apresentaram $100 \%$ de controle da população. A testemunha, após 141 dias, apresentou mais de $90 \%$ dos grãos danificados por esse inseto. 
Recentes estudos comprovam que a TD vem a ser um eficiente controle não químico contra $\boldsymbol{A}$. diaperinus. ALVES et al. (2006) avaliaram, em condições de laboratório, a eficiência da TD no controle dos cascudinhos em duas etapas. Na primeira, foram misturados 1, 2 e $3 g$ TD kg-1 de ração, com os adultos expostos durante 10 dias, nas temperaturas de 26 e $32^{\circ} \mathrm{C}$. Os autores registraram o efeito inseticida nas três concentrações, com mortalidade de 70, 83,3 e 90\%, respectivamente, não havendo diferença significativa entre as concentrações e a temperatura testada. $\mathrm{Na}$ segunda etapa, foram aplicados 86 e $172 \mathrm{~g} \mathrm{TD} \mathrm{m}^{-2}$ na cama de aviário, onde adultos foram expostos por 10 dias a $26^{\circ} \mathrm{C}$, a mortalidade alcançada foi de 49,1 e 78,1\%, respectivamente, com diferença significativa entre as concentrações, o que demonstra o potencial do uso de TD no controle de A. diaperinus.

\section{CONCLUSÃO}

Alphitobius diaperinus acarreta problemas sanitários nas granjas avícolas e interferência no desempenho zootécnico de frangos de corte, com sérios prejuízos financeiros.

Os métodos de controle por meio do uso de inseticidas químicos se mostram pouco eficientes e seguros em razão, principalmente, dos resíduos encontrados na carne das aves. Sendo assim, são necessários mais estudos na busca de produtos com princípios ativos não químicos, como, por exemplo, reguladores de crescimento, nematoides, fungos entomopatogênicos e terra diatomácea. O desenvolvimento industrial para produção em escala comercial e modo de aplicação eficaz e seguro aos animais e ao ambiente devem ser investigados em futuros trabalhos.

\section{REFERÊNCIAS}

AGUILLERA, M.M. et al. Controle biológico de Diloboderus abderus (Coleoptera: Melolonthidae): estudos preliminares com nematóides entomopatogênicos (Nematoda: Steinernematidae e Heterorhabditidae). In: REUNIÃO SUL BRASILEIRA DE PRAGAS DO SOLO, 8., 2001, Londrina. Anais... Londrina: Embrapa Soja, 2001. Doc.172, p.202207. Disponível em: <http://www.infoteca.cnptia.embrapa.br/ bitstream/CNPSO/18351/1/doc172.pdf $>$. Acesso em: 12 abr. 2009.

ALVES, L.F.A. et al. Ação da terra de diatomácea contra adultos do cascudinho Alphitobius diaperinus (Panzer, 1797) (Coleoptera: Tenebrionidae). Arquivos do Instituto Biológico, v.73, n.1, p.115-118, 2006. Disponível em: <http:/ /www.biologico.sp.gov.br/docs/arq/V73_1/alves.PDF>. Acesso em: 04 fev. 2009.
ALVES, L.F.A. et al. Patogenicidade de Steinernema glaseri e $\boldsymbol{S}$. carpocapse (Nematoda: Rhabdita) contra o cascudinho Alphitobius diaperinus (Panzer) (Coleoptera: Tenebrionidae) Neotropical Entomology, v.34, n.1, p.139-141, 2005. Disponível em: <http:/ /www.scielo.br/scielo.php?script=sci_arttext\&pid=S15195 $66 X 2005000100022 \& \operatorname{lng}=\mathrm{e} \& n \mathrm{~mm}=\mathrm{iso} \& \operatorname{tng}=\mathrm{pt}>$. Acesso em: 21 jan. 2009. doi: 10.1590/S1519-566X2005000100022.

ANON. Federal register. USA v.26, p.10228, 1961.

ARENDS, J.J. Control, management of the litter beetle. Poultry Digest v.28, p.172-176, 1987.

AXTELL, R.C.; ARENDS, J.J. Ecology and management of arthropod pests of poultry. Annual Review of Entomology, v.35, p.101-126, 1990. Disponível em: <http://arjournals.annualreviews.org/doi/abs/ 10.1146/annurev.en.35.010190.000533>. Acesso em: 13 fev. 2009. doi:10.1146/annurev.en.35.010190.000533.

BERTKE, E.M. The effect of ingestion of diatomaceous earth in white rats: a subacute toxicity test. Toxicology of Applied Pharmacology, v.6, p.284-291, 1964. Disponível em: < http:// www.sciencedirect.com/science?_ob=ArticleURL\&_udi=B6WXH4DD2KRD71\&_user $=10 \&$ \&_coverDate $=05 \% 2$ F31\%2F 1964 \&_r d o c $=5$ \& _f m t $=h$ i g h \&_or i g $=b r$ w se \& srch=docinfo(\%23toc\%237159\%231964\%2 3999939996\%23520910\%23FLA\%23dislay\%23Volume)\&_cdi=715 9\&_sort $=$ d\&_docanchor $=$ \&_ct $=16 \&$ \& acct $=$ C000050221\&_vers i o $n=1$ \& - u r l V e r s i o $n=0$ \& _ u s e r i d $=10 \& \mathrm{md} 5=47 \mathrm{f} 12 \mathrm{dfe} 252618$ ecaea3c405220acd25 >. Acesso em: 21 mar. 2009. doi:10.1016/0041-008X(64)90069-9.

CASAS, E. et al. Infection and quantitative recovery of Samonella typhimurium and Escherichia coli from within the lesser mealworm Alphitobius diaperinus (Panzer). Poultry Science, v.47, p.1871-1875, 1968.

CHERNAKI, A.M.; ALMEIDA, L.M. Exigências térmicas, período de desenvolvimento e sobrevivência de imaturos de Alphitobius diaperinus (Panzer) (Coleoptera: Tenebrionidae). Neotropical Entomology, v.30, n.3, p.365-368, 2001. Disponível em: <http:/ /www.scielo.br/scielo.php?script=sci_arttext \&pid= S1519566X2001000300004\&lng=en\&nrm=iso>. Acesso em: 14 abr. 2009. doi: 10.1590/S1519-566X2001000300004.

CHERNAKI-LEFFER, A.M. et al. Isolamento de enterobactérias em Alphitobius diaperinus e na cama de aviários no Oeste do Estado do Paraná, Brasil. Revista Brasileira de Ciência Avícola, v.4, n.3, p.243-247, 2002. Disponível em: <http:// www.scielo.br/scielo.php?script=sci_arttext \&pid=S1516635X2002000300009\&lng $=$ em\&nrm=iso $>$. Acesso em: 14 abr. 2009. doi: 10.1590/S1516-635X2002000300009 .

CHERNAKI-LEFFER, A.M. et al. Suscetibilidade de Alphitobius diaperinus (Panzer, 1797) (Coleoptera: Tenebrionidae) a reguladores de crescimento de insetos (RCI). Arquivos do Instituto Biológico, v.73, n.1, p.51-55, 2006.

DESPINS, J.L. et al. Construction profiles of high rise caged layer houses in association with insulation damage caused by the lesser mealworm, Alphitobius diaperinus (Panzer) in Virginia. Poultry Science, v.66, p 243-250, 1987.

DESPINS, J.L.; AXTELL, R.C. Feeding behavior and growth of broiler chicks fed larvae of the darkling beetle, Alphitobius diaperinus. Poultry Science, v.74, p.331-336, 1995.

EBELING, W. Sorptive dusts for pest control. Annual Review of Entomology, v.16, p.123-158, 1971. Disponível em: <http:/ / arjournals.annualreviews.org/doi/abs/10.1146/ 
annurev.en.16.010171.001011>. Acesso em: 27 fev. 2009. doi:10.1146/annurev.en.16.010171.001011

EBELING, W. et al. Influence of repellency on the efficacy of blatticides. Learned modification of behavior of the German cockroach. Journal Economic Entomology, v.59, n.6, p.1374-1388, 1966. Disponível em: <http:// esa.publisher.ingentaconnect.com/content/esa/jee/1966/ 00000059/00000006/art0001\#expand/collapse >. Acesso em: 27 fev. 2009.

ELOWNI, E.E. Biological studies on some cestodes parasites of the domestic fowl in the Sudan. 1977. 225f. Tesis (Master Degree) - University of Khartoum.

FERNANDES, M.A. et al. Ocorrência de artrópodes no esterco acumulado em uma granja de galinhas poedeiras. Anais da Sociedade Entomológica do Brasil, v.24, n.3, p.649-654. 1995.

GOODWIN, M.A.; WALTMAN, W.D. Transmission of Eimeria, viruses, and bacteria to chicks: darkiling beetles (Alphitobius diaperinus) as vectors of pathogens. Journal of Applied Poultry Research, v.5, p.51-55, 1996. Disponível em: <http://japr.fass.org/cgi/content/abstract/5/1/51>. Acesso em: 01 maio, 2009

JAPP, A.K. et al. Interferência no ganho de peso de frangos de corte alimentados com cascudinhos Alphitobius diaperinus Panzer (Coleoptera:Tenebrionidae). Revista Brasileira de Ciência Avícola, v.10, p.170, 2008.

KORUNIC, Z. Review Diatomaceous Earth, a group of natural insecticides. Journal Stored Product Research, v.34, n.23, p.8797, 1998. Disponível em: <http://www.sciencedirect.com/ science?_ob=ArticleURL\&_udi=B6T8Y-3TCWV8P_ $1 \&$ \&user $=10 \&$ \& coverDate $=04 \% 2$ F $07 \% 2$ F $1998 \&$ rdo $\mathrm{c}=1 \&$ \&_fmt $=$ high \&_orig=browse \&_sort=d\&view $=$ c \& a c c t $=$ C $000050221 \&$ \& e r s i o $n=1 \&$ _urlVersion=0\&_userid=10\&md5=2e10a62f801d3c71c5225628a4401aaf $>$. Acesso em: 03 maio, 2009. doi:10.1016/S0022-474X(97)00039-8.

KORUNIC, Z. et al. Diatomaceous earth an effective tool in integrated pest management. In: ANNUAL INTERNATIONAL RESEARCH CONFERENCE ON METHYL BROMIDE ALTERNATIVES AND EMISSIONS REDUCTIONS, 1996 Orlando, Florida. Proceedings... Orlando: US Environmental Agency and US Department of Agriculture, 1996. p.49.

LESCHEN, R.A.B.; STEELMAN, C.D. Alphitobius diaperinus (Coleoptera:Tenebrionidae) larva and adult mouthparts. Entomological News, v.99, n.4, p.221-224, 1988.

MATIAS, R.S. Cascudinho. Zeneca Saúde Pública, Junho, 2p., 1995.

MCALLISTER, J.C. et al. Isolation of infectious bursal disease virus from the lesser mealworm, Alphitobius diaperinus (Panzer). Poultry Science, v.74, p.45-49, 1995.

OMURA, T. Dynamic changes of protease inhibitors in workers exposed to diatomaceous earth dust. Averagi, v.30, n.2, p.181, 1981.

PINTO JR., A.R. et al. Controle de Acanthocelides obtectus (COLEOPTERA: BRUCHIDAE) com diferentes doses de terra diatomácea (dióxido de sílica). Revista Acadêmica: Ciências Agrárias e Ambientais, v.3, n.1, p.75-79, 2005. Disponível em: <http://www2.pucpr.br/reol/index.php/ACADEMICA?dd1=82>. Acesso em: 01 maio, 2009
SALIN, C. et al. Spatial distribution of Alphitobius diaperinus (Panzer) (Coleoptera: Tenebrionidae) in the soil of a poultry house along a breeding cycle. European Journal Soil Biology, v.36, p.107-115, 2000. Disponível em: < http://www.sciencedirect.com/ science? ob=ArticleURL\&_udi=B6VR7-41NK88Y$6 \&$ \&_us e r $=10 \&$ \&_c over D a t e $=04 \% 2$ F $06 \% 2$ F 2000 \&_rdoc $=6 \&$ \&_fmt $=$ high \&_orig=browse \&_srch $=$ docinfo( \% 23t oc \%236227\%232000\%23999639997\% $23218036 \% 23$ F L A \% 23 display\%23 Volume)\&_c $\mathrm{di}=6227 \&$ sort $=\mathrm{d} \&$ docanchor $=\& \quad \mathrm{ct}=6 \&$ a act $=\mathrm{C} 000050$ $221 \&$ version $=1 \&$ urlVersion $=0 \&$ userid $=10 \&$ md 5 =fa03b6e93a50efd6b272983939e5d0d6 > . Acesso em: 29 maio, 2009. doi:10.1016/S1164-5563(00)01054-2.

SILVA, A.S. et al. Ação do fungo Beauveria bassiana, isolado 986, sobre o ciclo biológico do cascudinho Alphitobius diaperinus em laboratório. Ciência Rural, v.36, n.6, p.1944-1947, 2006. Disponível em: <http://www.scielo.br/ s c i elo.php ? s c ri pt = s ci_art text \& pid = S 0103 $84782006000600047 \& \operatorname{lng}=$ pt\&nrm $=$ iso $>$. Acesso em: 07 maio, 2009. doi: 10.1590/S0103-84782006000600047.

SCHAFER DA SILVA, A. et al. Ciclo biológico do cascudinho Alphitobius diaperinus em laboratório. Acta Scientiae Veterinariae, v.33, n.2, p.177-181, 2005. Disponível em: <http://www.ufrgs.br/actavet/33-2/artigo624.pdf >. Acesso em: 08 maio, 2009.

SCHROCKENSTEIN, D.C. et al. Occupational sensitivity to Alphitobius diaperinus (Panzer) (Lesser mealworm). Journal Allergy Clinical Immunology, v.82, p.1081-1088, 1988.

SEGABINAZI, S.D.S. et al. Bactérias da família enterobacteriaceae em Alphitobius diaperinus oriundos de granja avícolas dos estados do Rio Grande do Sul e Santa Catarina. Acta Scientiae Veterinariae, v.33, n.1, p.51-55, 2005. Disponível em: <http:/ /www.ufrgs.br/actavet/33-1/artigo608.pdf>. Acesso em: 08 maio, 2009.

STATHERS, T.E. et al. The efficacy and persistence of diatomaceous earths admixed with commodity against four tropical stored product beetle pest. Journal of Stored Products Research., v.40, p.113123, 2004. Disponível em: <http://www.sciencedirect.com/ science? ob=ArticleURL\& udi=B6T8Y-483BRFD$4 \&$ \& user $=10 \&$ \&_cover Date $=12 \% 2$ F $31 \% 2$ F $2004 \&$ _rdoc $=1 \&$ \&_fmt $=$ high \&_orig=browse\&_sort $=$ d \& view $=$ c $\&$ _ c c $\mathrm{t}=\mathrm{C} 000050221 \&$ \& version $=1 \&$ \&_urlVersion $=0 \&$ \&userid $=10 \& \mathrm{md} 5=380 \mathrm{ffe} 25562 \mathrm{c} 4991 \mathrm{e} 4 \mathrm{~d} 1 \mathrm{a} 9 \mathrm{~d} 6 \mathrm{fb} 4244 \mathrm{~d} 0>$. Acesso em: 03 maio, 2009. doi:10.1016/S0022-474X(02)00083-8.

WALLACE, M.M.H. et al. The use a beetle, Alphitobius diaperinus (Panzer) (Coleoptera: Tenebrionidae) for the biological control of poultry dung in high-rise layer houses. Journal of the Australian Institute of Agricultural Science, v.51, n.3, p.214-219, 1985.

VAUGHAN, J.A. et al. Infestation and damage of poultry house insulation by the lesser mealworm, Alphitobius diaperinus (Panzer). Poultry Science, v.63, p.1094-1100, 1984.

VERGARA, C.; GAZANI, R. Biologia de Alphitobius diaperinus (Panzer) (Coleoptera: Tenebrionidae). Revista Peruana de Entomologia, v.39, p.1-5, 1996.

VITTORI, J. et al. Alphitobius diaperinus como veiculador de Clostridium perfrigens em granjas avícolas do interior paulista - Brasil. Ciência Rural, v.37, n.3, p.894-896, 2007. Disponível em: <http:/ /www.scielo.br/scielo.php?script=sci_arttext\&pid=S0103$84782007000300048 \& \operatorname{lng}=$ pt\&nrm=iso $>$. Acesso em: 20 maio, 2009. doi: 10.1590/S0103-84782007000300048. 